\title{
Modification of concrete mortar using polyurethane resin
}

\author{
Ibrahim Aminu Inuwa * and Abubakar Musa Yola \\ Nigerian Building \& Road Research Institute, NBRRI House 10 I.T. Igbani Street, Off Obafemi Awolowo Way, Jabi PMB \\ 5065 Abuja, FCT, Nigeria.
}

World Journal of Advanced Engineering Technology and Sciences, 2021, 02(02), 079-083

Publication history: Received on 10 April 2021; revised on 19 May 2021; accepted on 22 May 2021

Article DOI: https://doi.org/10.30574/wjaets.2021.2.2.0041

\begin{abstract}
This paper presents an experimental investigation carried out to study the effects of non-water soluble Polyurethane Resin used in the modification of concrete mortar. The non-water soluble Polyurethane Resin (PU) was obtained from Fursa Industry and Tech Limited. The non-water soluble PU was used for this study do to its availability and low cost. Additives such as; Sulphur and Calcium Oxide responsible for binding and curing were used. Concrete mortar cubes of 50 x 50 × 50 mm respectively were produced with grade 42.5 Ordinary Portland Cement from Dangote Cement Limited. The ordinary Portland Cement was partially replaced with $0 \%$ (control), 15\%, 25\% and 35\% non-water soluble Polyurethane Resin respectively. The influence of partial replacing Ordinary Portland Cement with non-water soluble Polyurethane was checked by testing the concrete mortar cubes for compressive strength testat7, 14 and 28 days respectively after casting and curing. It was observed that the addition of Polyurethane Resin as OPC partial replacement leads to considerable increase in compressive strength at $25 \%$ and $35 \%$ in comparison to the compressive strength of the control sample. The improvement in compressive strength was not significant beyond 35\% Polyurethane replacement of OPC and was there accepted as the optimum percentage replacement
\end{abstract}

Keywords: Polyurethane; Resin

\section{Introduction}

Developments in civil engineering and industrial growth have created a continual demand for building materials with new and improved performance attributes. Nowadays, requirements to be met by construction materials include not only strength features but also chemical resistance, resulting from the increasing contamination of the natural environment, leading to the need to protect and increase the durability of building structures. Unfortunately, cement manufacturing consumes large amount of energy amounting about $7.36^{*} 106 \mathrm{~kJ}$ per ton of cement (Tarun, 1996). Also, approximately 1 ton of $\mathrm{CO}_{2}$ is released into the atmosphere during the production of 1 tonne of cement (Min-Hong, 2001). Thus partial replacement of Portland cement in mortar / concrete with Polymer.

Polymer modified concrete is an innovative and modern material that satisfies all the strict requirements of durability and chemical resistance, while offering high mechanical strength. On the other hand all efforts are made in other to reduce demand on cement as a result of the enormous amount of carbon dioxide release during manufacturing. It has been estimated that the manufacturing process of OPC produce $7 \%$ of the global $\mathrm{CO}_{2}$ emission (Suleiman et al, 2012). This trend is adding 1.6 billion tons of $\mathrm{CO}_{2}$ into the atmosphere (Mehta, 2003).

Concrete mortar made with Ordinary Portland cement has been a popular construction material in the world for the past 170 years or more. However, due to the low tensile strength, delayed hardening, high drying shrinkage, and low

${ }^{*}$ Corresponding author: Ibrahim A. Inuwa

Nigerian Building \& Road Research Institute, NBRRI House 10 I.T. Igbani Street, Off Obafemi Awolowo Way, Jabi PMB 5065 Abuja, FCT, Nigeria. 
chemical resistance, this study focuses on how to reduce these disadvantages by partial replacement of Ordinary Portland Cement with non-water soluble polyurethane resin. This can be achieved by investigating the impact of nonwater soluble polyurethane on the compressive strength of concrete mortar and the mortar's water absorption, when used as partial replacement of ordinary Portland cement. Due to its excellent bonding ability, high workability and high resistance to aggressive environments, Polymer Modified Concrete finds applications in overlays of industrial floors and rehabilitation of deteriorated bridge decks. Non-water soluble polyurethane resin was obtained from Fursa Tech and Industry, Abuja Nigeria.

\subsection{Aim and Objectives}

The aim of this research was to investigating the effects of non-water soluble Polyurethane Resin used in the modification of concrete mortar. The objectives of the study includes:

- To determine the impact of non-water soluble polyurethane resin on the compressive strength of concrete mortar.

- To determine the optimum partial replacement of ordinary Portland cement with non-water soluble Polyurethane resin in concrete mortar

\section{Material and methods}

\subsection{Materials}

The grade 42.5 Dangote Ordinary Portland cement was sourced here in Abuja and used for the study.The study was performed using Polyurethane resin non-water soluble purchased from Fursa Tech and Industry Limited, Abuja. Binding and curing additives were also purchased from Aba Market, Abia state Nigeria.Fine aggregate used was river sand and passed through sieved $2 \mathrm{~mm}$ and retained in 90 microns sieve.

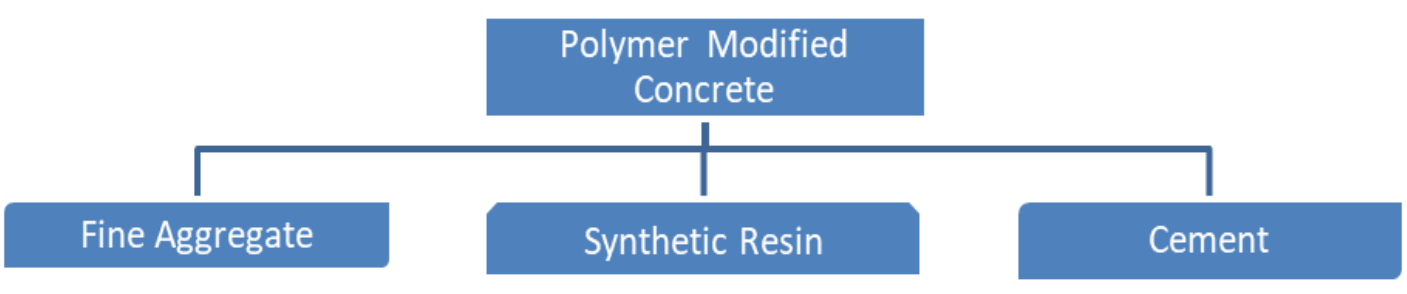

Aggregate mixture: Including a hardener responsible Ordinary Portland Cement Sand passing sieve $2 \mathrm{~mm}$ for binding and curing time

\subsection{Preparation of Mortar Cubes}

Previous research by Chmykov (2005) established 35\% as the optimum PU resin content that produce optimum compressive strength of concrete. In this study, the compressive strength of concrete mortar for up to $35 \%$ Polyurethane partial replacement of ordinary Portland cement was investigated .Eight blended Polyurethane modified mortar cube in $50 \mathrm{~mm} \times 50 \mathrm{~mm} \times 50 \mathrm{~mm}$ sized moulds were prepared in the order of $0 \%, 15 \%, 25 \%$ and $35 \%$ by mass of polyurethane. 35\% water to Polyurethane resin/ordinary Portland cement binder by mass used. For all the mixes 1:6 mix ratio of binder to fine sand was used.

Water was added and mixed until the mixture is of uniform color. The mixing lasted about3 minutes. Immediately after mixing, the mortar was poured into the cube mould and prodded with the help of the rod. The mortar was prodded 20 times in about $8 \mathrm{sec}$ to ensure elimination of entrained air. Then the cube moulds were allowed to cure at room temperature of $27 \pm 2^{\circ} \mathrm{C}$ and $90 \%$ relative humidity for 24 hours. After 24 hours the cubes were removed from the mould and immediately submerge in clean water till testing. The cubes were subjected to a uniform loading at the rate of $2.4 \mathrm{kN} / \mathrm{sec}$. Test was conducted for 3 cubes and recorded the average value as the test result for 7 days, 14 days and 28 day compressive strength. The summary of mix proportion for each cement mortar is presented in Table 1. 
Table 1Experimental Design

\begin{tabular}{|l|l|l|l|l|}
\hline Mix (\%) & Water (g) & Sand (g) & OPC (g) & PU (g) \\
\hline 0 & 120 & 1062 & 211 & 0 \\
\hline 15 & 120 & 1062 & 180 & 31 \\
\hline 25 & 120 & 1062 & 160 & 51 \\
\hline 35 & 120 & 1062 & 140 & 71 \\
\hline
\end{tabular}

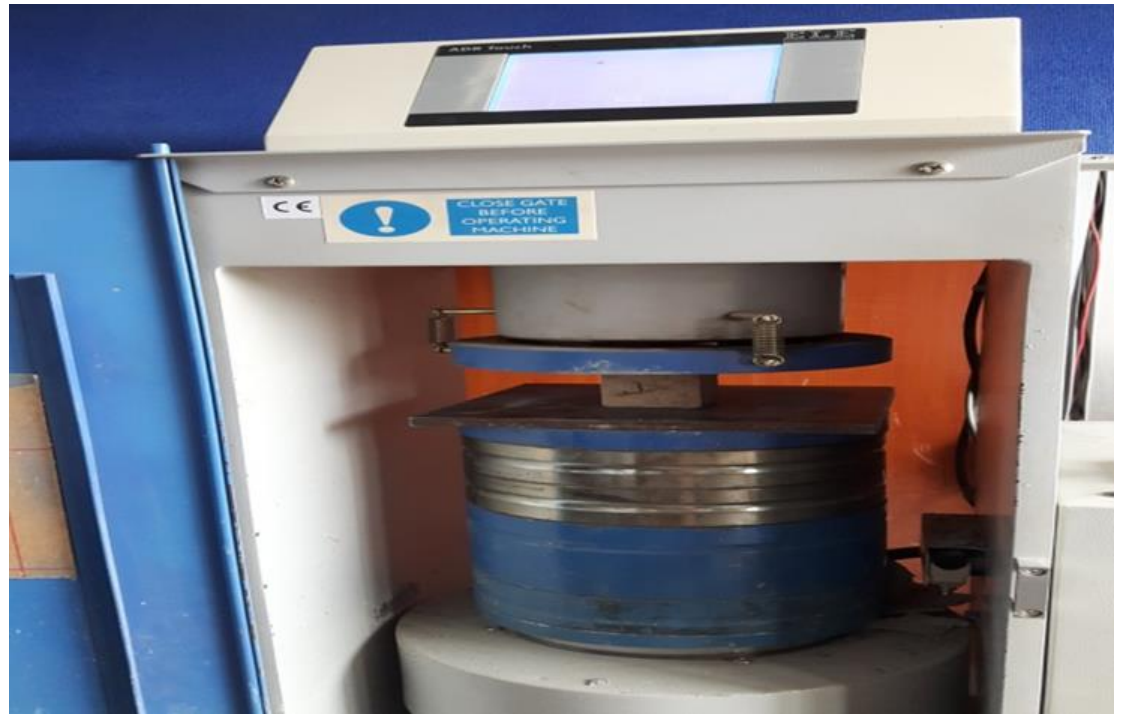

Figure 1 Compressive Strength test on mortar

\subsection{Compressive Strength Test}

The preparedspecimenswerecuredfor7 days, 14 days and 28 days each and were tested for compressive strength, according to BS 1881-116:1983 using universal testing machine as shown in Figure 5. Three samples of each category (Table 2) were prepared and the stress at failure was measured

\section{Results and discussion}

\subsection{Compressive Strength Test}

The compressive strength of Polymer modified as listed in table 2, has been graphically presented in figure 2 . All the mixes for 15\% PU replacement of OPC at 7 days compressive strength, no PMC achieved maximum strength compared to the $0 \%$ (control sample) that had $3 \mathrm{~N} / \mathrm{mm}^{2}$. Test results showed that the 7 days compressive strength of $25 \% \mathrm{PU}$ replacement of OPC rose to $9 \mathrm{~N} / \mathrm{mm}^{2}$, higher than the $0 \%$ (control sample) at $3 \mathrm{~N} / \mathrm{mm}^{2}$.Similar trend was observed for $35 \%$ replacement. The maximum compressive strength of $11 \mathrm{~N} / \mathrm{mm}^{2}$ was attained at $35 \%$ Polyurethane replacement of OPC. This trend shows that the addition of PU as partial replacement of Ordinary Portland Cement has negligible effect on the compressive strength of mortar at 15\%. However, at higher percentage replacement beyond $15 \%$, the compressive strength for all the mixes are higher than the control samples. These results further confirm the similar previous studies which concluded that Polyurethane resin of hydrophobic class, when mixed with concrete increases its compressive strength significantly [2] 
World Journal of Advanced Engineering Technology and Sciences, 2021, 02(02), 079-083

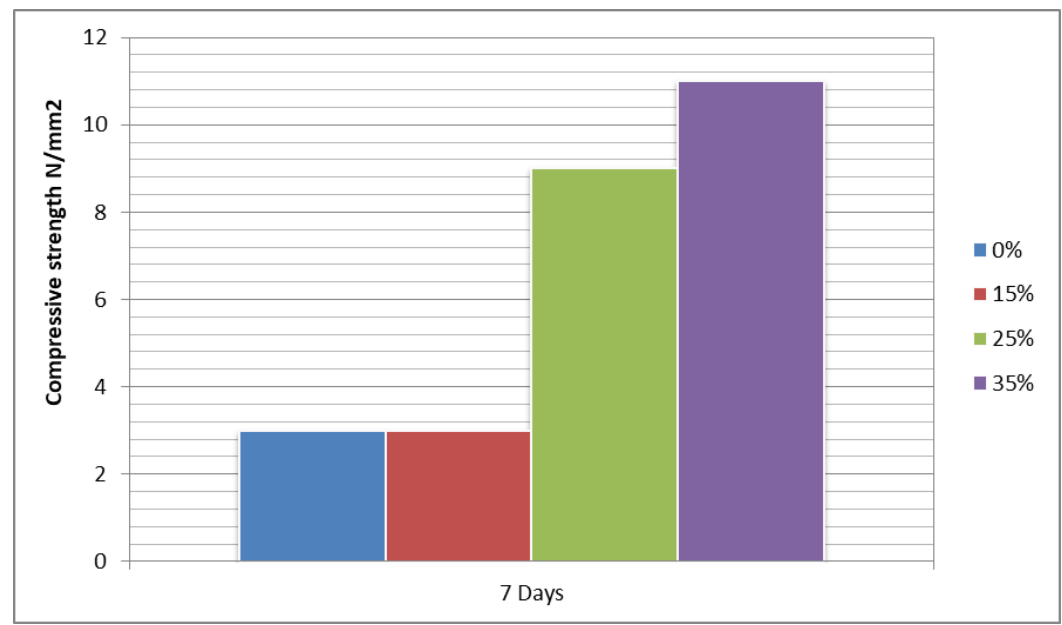

Figure 2 Percentage Replacement of PU Resin in OPC at 7 Days

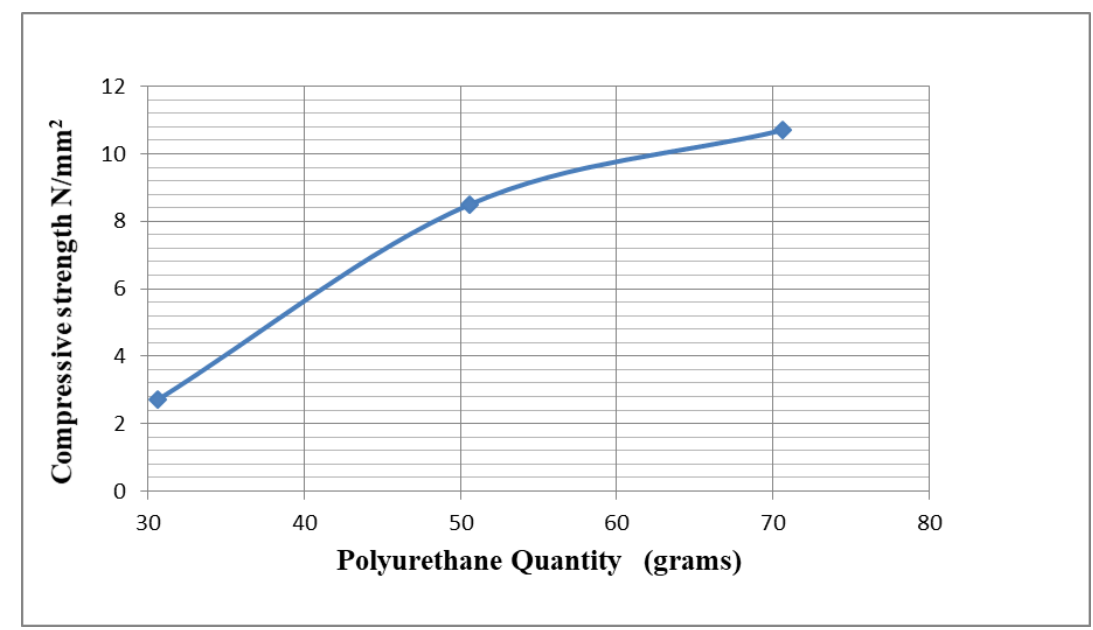

Figure 3 Compressive strength vs quantity of PU

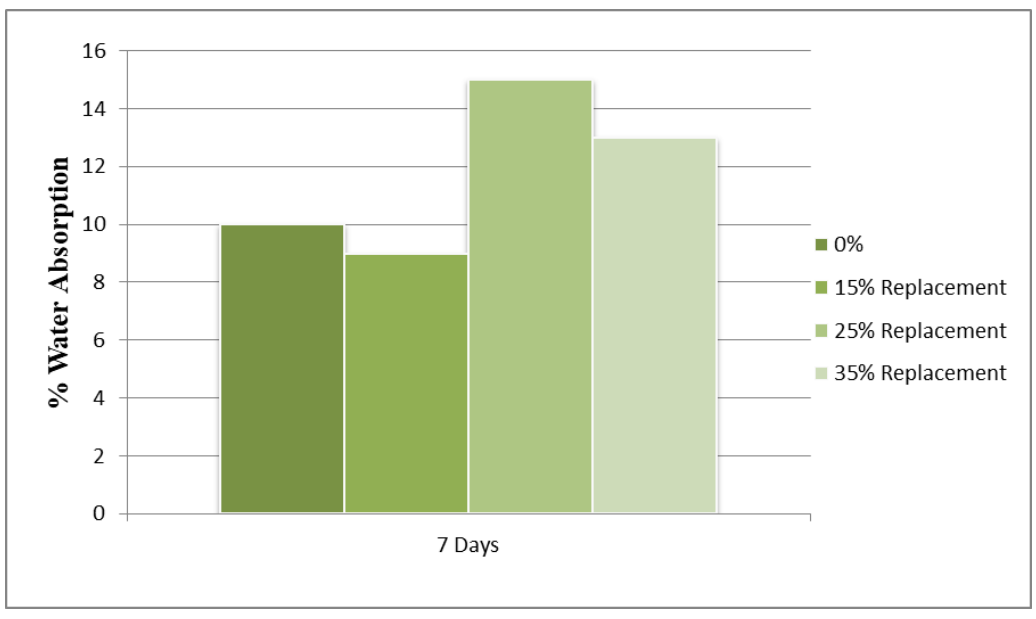

Figure 4 Water Absorption 


\section{Conclusion}

Based on the results of the investigation conducted on different PU modified mortars made with various level of cement replacement and cured for 7 days period, the following conclusions can be drawn. The use of non-water soluble polyurethane resin for the replacement of ordinary Portland cement in concrete mortar was found to increase the compressive strength with increase percentage replacement

\section{Compliance with ethical standards}

\section{Acknowledgments}

I would like to extend my words of appreciation and gratitude to my Director General and Chief Executive Officer in person of Professor Samsun Duna, For his mentorship and support throughout the study period as well as my co-author Engineer Abubakar M.Yola for his immeasurable dedication in carrying out this research and also to my office Nigerian Building and Road Research Institute who gave us the perfect atmosphere to conduct this wonderful study.

Lastly i would like to thank my colleagues who helped me immensely in finishing this research within a limited period,it helped me increase my knowledge and skills.

\section{Disclosure of conflict of interest}

Authors declare that they do not have conflict of interest.

\section{References}

[1] Larbi JA, Bijen MJM. Bond Strength Development between Latex Modified.

[2] Larbi JA, Bijen MJM. Influence of Polymer Modification on the Hydration of Portland Cement. Cement and Concrete Research. 1990; 21: 242-250.

[3] Lewis WJ,Lewis G. The Influence of Polymer Latex Modifies on the Properties of Concrete. Composites. 1990; 21(6): 487-494.

[4] Gorninski JP, Dal Molin DC. Comparative Assessment of Isophtalic and Orthophtalic Polyester Polymer Concrete. Construction and Building Materials. 2007; 21: 546-555, 2007.

[5] Agavriloaie L, Oprea S, Barbuta M, Luca M. Characterization of Polymer Concrete with Epoxy Polyurethane Acryl Matrix. Construction and Building Materials. 2012; 31: 190-196.

[6] Isamail M, Muhammad B. Performance of Natural Rubber Latex Modified Concrete in Acidic and Sulphated Environment. Construction and Building Materials. 2012; 31: 129-134.

[7] Tarun R, Naik, Shiw S Singh, Mohammad M. Hossain. Permeability of High Strength Concrete Containing Low Cement Factor, Journal of Energy Engineering. 1996; 122(1): 21-39. 